\title{
Pre-transport management of primary percutaneous coronary intervention network patients
}

\section{(D) Jadranka Daskijević* \\ University Hospital Centre „Sestre milosrdnice“, Zagreb, Croatia}

RECEIVED:

February 19, 2020

ACCEPTED:

February 22, 2020

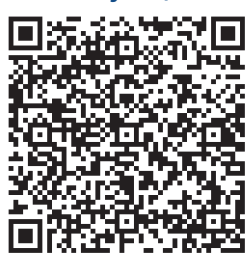

$\square$ Cardiologia Croatica 2020;15(3-4):62
KEYWORDS: acute coronary syndrome, management, transport

CITATION: Cardiol Croat. 2020;15(3-4):62. | https://doi.org/10.15836/ccar2020.62

*ADDRESS FOR CORRESPONDENCE: Jadranka Daskijević, KBC Sestre milosrdnice, Vinogradska cesta 29, HR-10000 Zagreb, Croatia. / Phone: +385-98-570-842 / E-mail: jadranka.daskijevic@kbcsm.hr

ORCID: Jadranka Daskijević, https://orcid.org/0000-0001-6547-1098

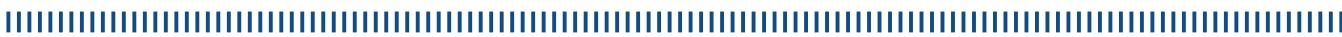

Croatian Primary Percutaneous Coronary Intervention Network, founded in 2005, is an internationally recognized system of well-organized urgent treatment of cardiology patients. ${ }^{1}$ The project Croatian Interventional Treatment Network for Acute Myocardial Infarction is one of the most significant achievements in the field of contemporary cardiology in Croatia, but also in the field of medicine in general. Thousands of lives have been saved thanks to a network of heart attack interventions. The transfer of patients to another facility is arranged between the cardiologists on duty at both institutions. The patient is transported by ambulance accompanied by physician and a nurse/technician. Emergencies pose a specific challenge for the nurse/technician, where it is necessary to anticipate which complications can be avoided by good organization. In these emergencies, patients should be well prepared for the invasive and therapeutic procedure, as this results in a timely and effective revascularization of the lesion that caused the acute myocardial infarction. Health care of the patient, its prior continuity, as well as care during and after the procedure is extremely important for the patient's recovery. The mental preparation of the patient reduces the level of fear and concern, and thus facilitates the intervention of team members. The information given to the patient must be understandable, detailed and simple. In the case of the physical preparation of patients, oral and parenteral therapy is required in addition to laboratory tests, according to the physician's instructions and general condition of the patient, as well as mandatory informed consent to perform the examination which the patient must sign if capable. It is recommended to place two vein pathways, preferably cubital, to remove hair from both groin and wrists, to remove the denture if the patient has it, to remove all jewelry, glasses, lenses, nail polish, to relieve the patient of unnecessary clothing and footwear and to warm the patient. All team members work for the best possible outcome. Such a difficult and lifethreatening condition requires immediate and instant interventions, as any delay lowers the chances of ultimate success of the procedure.

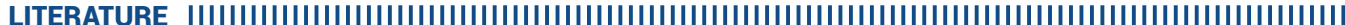

1. Nikolić Heitzler V, Babic Z, Milicic D, Bergovec M, Raguz M, Mirat J, et al. Results of the Croatian Primary Percutaneous Coronary Intervention Network for patients with ST-segment elevation acute myocardial infarction. Am J Cardiol. 2010 May 1;105(9):1261-7. https://doi.org/10.1016/j.amjcard.2009.12.041 